\title{
Women's Healthcare Utilization Following Routine Screening for Past-Year Intimate Partner Violence in the Veterans Health Administration
}

\author{
Melissa E. Dichter, PhD ${ }^{1,2}$, Anneliese E. Sorrentino, MSS' , Terri N. Haywood, MPH', \\ Scarlett L. Bellamy, ScD ${ }^{3}$, Elina Medvedeva, $\mathrm{MS}^{7}$, Christopher B. Roberts, $\mathrm{MPH}^{7}$, and \\ Katherine M. Iverson, $P h D^{4,5}$
}

\begin{abstract}
${ }^{1}$ Center for Health Equity Research and Promotion, U.S. Department of Veterans Affairs, Philadelphia, PA, USA; ${ }^{2}$ Department of Family Medicine and Community Health, University of Pennsylvania Perelman School of Medicine, Philadelphia, PA, USA; ${ }^{3}$ Department of Epidemiology and Biostatistics, Drexel University Dornsife School of Public Health, Philadelphia, PA, USA; “Women's Health Sciences Division, National Center for PTSD, VA Boston Healthcare System, Boston, MA, USA; ${ }^{5}$ Department of Psychiatry, Boston University School of Medicine, Boston, MA, USA.
\end{abstract}

BACKGROUND: Experience of intimate partner violence (IPV) can have adverse health impacts and has been associated with elevated rates of healthcare service utilization. Healthcare encounters present opportunities to identify IPV-related concerns and connect patients with services. The Veterans Health Administration (VHA) conducts IPV screening within an integrated healthcare system.

OBJECTIVE: The objectives of this study were to compare service utilization in the 6 months following IPV screening between those screening positive and negative for pastyear IPV (IPV+, IPV-) and to examine the timing and types of healthcare services accessed among women screening IPV+.

DESIGN: A retrospective chart review was conducted for 8888 female VHA patients across 13 VHA facilities who were screened for past-year IPV between April 2014 and April 2016.

MAIN MEASURES: Demographic characteristics (age, race, ethnicity, marital status, veteran status), IPV screening response, and healthcare encounters (based on visit identification codes).

KEY RESULTS: In the 6 months following routine screening for past-year IPV, patients screening IPV+ were more likely to utilize outpatient care $(\mathrm{aOR}=1.85$ [CI 1.26 , 2.70]), including primary care or psychosocial care, and to have an inpatient stay $(\mathrm{aOR}=2.09$ [CI 1.23, 3.57]), compared with patients screening IPV-. Among those with any utilization, frequency of outpatient encounters within the 6-month period following screening was higher among those screening IPV+ compared with those screening IPV-. The majority of patients screening positive for past-year IPV returned for an outpatient visit within a brief time frame following the screening visit (> 70\% within 14 days, >95\% within 6 months). More than one in four patients screening IPV+ had an emergency department visit within the 6 months following screening.

CONCLUSIONS: Women who screen positive for past-year IPV have high rates of return to outpatient visits following

Received October 20, 2017

Revised December 19, 2017

Accepted January 16, 2018

Published online February 8, 2018 screening, presenting opportunities for follow-up support. Higher rates of emergency department utilization and inpatient stays among women screening IPV+ may indicate adverse health outcomes related to IPV experience.

KEY WORDS: intimate partner violence; service utilization; Veterans Health Administration

J Gen Intern Med 33(6):936-41

DOI: $10.1007 / \mathrm{s} 11606-018-4321-1$

(C) Society of General Internal Medicine (outside the USA) 2018

\section{INTRODUCTION}

Intimate partner violence (IPV), including physical, sexual, and psychological violence from a current or former intimate partner, is a public health concern affecting 5.3 million women in the USA each year. ${ }^{1}$ Experience of IPV is associated with elevated rates of multiple chronic and acute physical and mental health conditions, ${ }^{2-6}$ as well as social health needs (e.g., housing, employment), ${ }^{7-9}$ and healthcare use and costs. $^{10-14}$

Healthcare encounters, whether specifically related to IPV health impacts or not, present opportunities to both identify and provide patients with support related to IPV and its aftermath. Women experiencing IPV may be able to safely attend healthcare visits, especially in primary care, without suspicion from an abusive partner or stigma associated with seeking social services. The healthcare encounter offers a chance for trained healthcare personnel to assist patients experiencing IPV through supportive counseling, validation of their experiences, education, and information about and linkages to resources to promote their safety and recovery. Accordingly, IPV screening and response have been recommended for primary care and emergency department encounters, as well as in mental health, obstetrics/gynecology, pediatric, and dental care settings. ${ }^{15-23}$

Women veterans face higher rates of lifetime IPV exposure compared to women who have not served in the military. ${ }^{4}$ 
Nearly one in five women veterans enrolled in primary care through the Veterans Health Administration (VHA) experience IPV within a single year ${ }^{24}$ and one in 12 disclose pastyear IPV to VHA healthcare providers in response to clinical screening. ${ }^{25}$ The VHA has recently implemented routine screening of female patients for experience of past-year IPV using the Extended-Hurt, Insult, Threaten, Scream (E-HITS) scale, ${ }^{26}$ which asks about frequency of psychological, physi$\mathrm{cal}$, and sexual violence perpetrated by a current or former intimate partner in the past 12 months. This screening, conducted primarily in primary care but with variation in administration across sites, is used to identify patients experiencing IPV and offer follow-up assessment and intervention services within VHA or community agencies as appropriate.

In this study, we examined electronic health record data (retrospective chart review) to examine the relationship between IPV exposure and healthcare service use among a large cohort of female VHA patients screened for experience of past-year IPV within the context of routine care. This study extends prior research on this relationship ${ }^{10-13}$ to the VHA setting and patient population, and compensates for limitations of prior studies that relied on research survey participation ${ }^{13}$ or ad hoc documentation of spontaneous disclosures in healthcare records. ${ }^{14,23,24}$ As VHA is a nationwide integrated healthcare system, use of electronic health record data allows for analysis of a large sample from sites across the country and inclusion of primary, specialty, mental health, and emergency outpatient and inpatient care. The specific objectives of this study were to (a) compare service utilization in the 6 months following IPV screening between those screening positive and negative for past year IPV (IPV+ vs. IPV-) and (b) examine the types of healthcare services women who have experienced IPV are accessing following disclosure of IPV experience through routine screening. Analysis of these data provides information about potential resource needs for patients experiencing recent IPV, as well as opportunities for further intervention among this patient population.

\section{METHODS}

Data were extracted from the VHA Corporate Data Warehouse, a repository of VHA electronic health records aggregated from all VHA facilities nationwide, for all female VHA patients who had documentation of a completed IPV screening using the E-HITS screening tool ${ }^{26}$ in their electronic health record between April 2014 and April 2016. The study was approved by the Corporal Michael J. Crescenz VA Medical Center institutional review board, including a waiver of informed consent.

\section{Measures}

Demographic characteristics at the time of IPV screening were extracted from electronic health records and included age, race, ethnicity (Hispanic/Latina or not), marital status, and veteran status (some VHA facilities provide care to non- veteran spouses or dependents of eligible veterans). IPV status was defined by routine screening using the E-HITS measure. The E-HITS includes five items, each with a five-point Likert scale, with points ranging from 1 ("never") to 5 ("frequently") and sum scores ranging from 5 to 25 . A score of 7 or higher is considered positive for past-year IPV. ${ }^{27}$ For women who had multiple IPV screenings documented in the health records, we defined the index screen as the first positive screen or, if no positive screens, the first screen. Health services use data were determined based on "stop codes," numeric identifiers for each patient encounter. Stop codes were categorized into types of services: psychosocial (including mental health, drug or alcohol treatment, and social services), primary care, emergency department, other outpatient (i.e., specialty care), and any inpatient admission.

\section{Analysis}

We summarized demographic characteristics and health service use within 6 months following IPV screening of the study cohort overall and by IPV status (IPV+, IPV-) groups using frequencies and corresponding percentages. For women screening IPV+, we summarized visit frequencies for each health service type within $14,30,60$, and 180 days following screening, not including the encounter in which screening occurred but including additional encounters on the same day of screening.

We compared service utilization (yes/no for each category of healthcare visits) between women screening IPV+ and those screening IPV- using chi-square tests and the median number of visits among IPV+ and IPV- women using Wilcoxon non-parametric tests. For patients who had at least one visit, we calculated the median number of visits and interquartile range.

We employed a zero inflated Poisson (ZIP) model as our primary analytical approach to examine the relationship between IPV status and visit frequencies for each health service type. ZIP regression is used to model count data that has an excess (e.g., more than would be expected from a typical Poisson process) of zero counts. Statistical theory suggests that the excess zeros are generated by a separate, independent process; as such, ZIP models have two parts: (1) a typical Poisson count model and (2) a logistic model for the excess zeros. For the Poisson part of the model, we considered IPV status (positive/negative) as the primary exposure of interest in estimating the association with the number of visits (a count) within 6 months following the index IPV screen for each health service type. Similarly, the logistic part of the mixture model estimates the probability of having no visit (e.g., excess zero yes/no) for each respective health service type in the 6 months following IPV screening. Model estimates are presented as odds ratios (ORs) and corresponding 95\% confidence intervals (CIs) for the logistic part of the model and as rate ratios (RRs) and corresponding 95\% CIs for the Poisson part of the model. These models also account for the potential 
clustering by VA facility and were fit using the NLMIXED procedure in SAS (version 9.4; SAS Institute Inc.).

We fit two models for each health service type. The first ZIP model included our primary exposure of interest only, IPV status. Next, we further adjusted ZIP models for age, race, marital status, and veteran status as these are factors known to be associated with variation in VHA healthcare use. ${ }^{28}$ All analyses were performed using SAS software (version 9.4; SAS Institute Inc.).

\section{RESULTS}

\section{Sample Description}

The sample included 8888 female patients, 774 (8.7\%) of whom screened positive for past-year IPV experience (IPV+). Table 1 presents demographic characteristics and healthcare service use within 6 months following the index IPV screen, for the sample overall and by IPV status (note: comparisons of demographic characteristics by IPV status are available for this sample in a previous publication). ${ }^{25}$ About half of the patients in the sample were under age 45 years, with a larger proportion of younger patients in the IPV+ group. Just over half of the sample was identified as White, and approximately $90 \%$ was identified as not Hispanic or Latina; approximately one third were married. Nonveterans $(5.2 \%)$ included patients eligible for VHA due to their relationship as a spouse or veteran of eligible veteran.

The overwhelming majority $(91.8 \%)$ of all patients returned for an outpatient encounter within 6 months following the index IPV screen. Just under half $(47.7 \%)$ of IPV- patients and three-quarters $(74.9 \%)$ of IPV+ patients had a psychosocial encounter within this time frame. Close to $70 \%$ of IPVand $75 \% \mathrm{IPV}+$, patients had a primary care encounter. Approximately one in five IPV- patients and more than one in four IPV+ patients had an emergency department encounter in the 6 months following IPV screening. Four percent of IPVpatients and $7.1 \%$ of IPV+ patients received inpatient care within the study time frame. Among those with any outpatient encounter during the 6 months following IPV screening, the median number of encounters was 7 for the IPV- group $(\mathrm{IQR}=3,14)$ and 11 for the IPV+ group $(\mathrm{IQR}=5,20)$.

\section{Visit Frequency by IPV Status}

In both unadjusted and adjusted models, patients screening IPV+ were nearly twice as likely as those screening IPV- to receive any outpatient services and more than three times as likely as those screening IPV- to receive any psychosocial care within 6 months following IPV screening (Table 2). Odds of having any primary care visit within the 6-month period post-screening were also higher among the IPV+ versus IPV- group, and when adjusting for demographic characteristics (age, race, marital status, veteran status), women screening IPV+ were also more likely than those screening IPV- to have an inpatient stay in the 6 months following IPV screening.
Table 1 Sample Demographic Characteristics and Post-screening Healthcare Service Utilization by Past-Year Intimate Partner Violence

\begin{tabular}{|c|c|c|c|c|}
\hline & $\begin{array}{l}\text { Total } \\
N=\mathbf{8 8 8 8}\end{array}$ & $\begin{array}{l}\text { IPV- } \\
N=8114\end{array}$ & $\begin{array}{l}\text { IPV+ } \\
N=774\end{array}$ & $\begin{array}{l}P \text { value } \\
\text { for IPV+ } \\
\text { vs. IPV- }\end{array}$ \\
\hline & $N(\%)$ & $N(\%)$ & $N(\%)$ & \\
\hline \multicolumn{4}{|l|}{ Age* } & \multirow[t]{7}{*}{$<0.001$} \\
\hline Mean (SD) & $\begin{array}{l}45.0 \\
(13.7)\end{array}$ & $\begin{array}{l}45.3 \\
(13.9)\end{array}$ & $\begin{array}{l}41.9 \\
(12.1)\end{array}$ & \\
\hline$<35$ & $\begin{array}{l}2512 \\
(28.3)\end{array}$ & $\begin{array}{l}2248 \\
(27.7)\end{array}$ & $\begin{array}{l}264 \\
(34.1)\end{array}$ & \\
\hline $35-44$ & $\begin{array}{l}2001 \\
(22.5)\end{array}$ & $\begin{array}{l}1812 \\
(22.3)\end{array}$ & $\begin{array}{l}189 \\
(24.4)\end{array}$ & \\
\hline $45-54$ & $\begin{array}{l}1993 \\
(22.4)\end{array}$ & $\begin{array}{l}1811 \\
(22.3)\end{array}$ & $\begin{array}{l}182 \\
(23.5)\end{array}$ & \\
\hline $55-64$ & $\begin{array}{l}1751 \\
(19.7)\end{array}$ & $\begin{array}{l}1635 \\
(20.2)\end{array}$ & $\begin{array}{l}116 \\
(15.0)\end{array}$ & \\
\hline$\geq 65$ & $631(7.1)$ & $608(7.5)$ & $23(3.0)$ & \\
\hline Race & & & & \multirow[t]{6}{*}{0.366} \\
\hline White & $\begin{array}{l}4678 \\
(52.6)\end{array}$ & $\begin{array}{l}4258 \\
(52.5)\end{array}$ & $\begin{array}{l}420 \\
(54.3)\end{array}$ & \\
\hline Black or African- & 3399 & 3124 & 275 & \\
\hline American & $(38.2)$ & $(38.5)$ & $(35.5)$ & \\
\hline Other & $312(3.5)$ & $281(3.5)$ & $31(4.0)$ & \\
\hline Missing & $499(5.6)$ & $451(5.6)$ & $48(6.2)$ & \\
\hline Ethnicity & & & & \multirow{5}{*}{0.818} \\
\hline Hispanic or Latina & $495(5.6)$ & $451(5.6)$ & $44(5.7)$ & \\
\hline Not Hispanic or & 8006 & 7313 & 693 & \\
\hline Latina & $(90.1)$ & $(90.1)$ & $(89.5)$ & \\
\hline \multirow{2}{*}{\multicolumn{4}{|c|}{ Marital status* }} & \\
\hline & & & & \multirow[t]{4}{*}{$<0.001$} \\
\hline Married & $\begin{array}{l}3097 \\
(34.8)\end{array}$ & $\begin{array}{l}2780 \\
(34.3)\end{array}$ & $\begin{array}{l}317 \\
(41.0)\end{array}$ & \\
\hline Not married $\dagger$ & $\begin{array}{l}5661 \\
(63.7)\end{array}$ & $\begin{array}{l}5220 \\
(64.3)\end{array}$ & $\begin{array}{l}441 \\
(57.0)\end{array}$ & \\
\hline Missing & $130(1.5)$ & $114(1.4)$ & $16(2.1)$ & \\
\hline \multicolumn{4}{|l|}{ Veteran* } & \multirow[t]{3}{*}{$<0.001$} \\
\hline No & $461(5.2)$ & $397(4.9)$ & $64(8.3)$ & \\
\hline Yes & $\begin{array}{l}8427 \\
(94.8)\end{array}$ & $\begin{array}{l}7717 \\
(95.1)\end{array}$ & $\begin{array}{l}710 \\
(91.7)\end{array}$ & \\
\hline \multicolumn{5}{|c|}{ Healthcare encounter within 6 months following IPV screen* } \\
\hline Any outpatient & $\begin{array}{l}8160 \\
(91.8)\end{array}$ & $\begin{array}{l}7423 \\
(91.5)\end{array}$ & $\begin{array}{l}737 \\
(95.2)\end{array}$ & $<0.001$ \\
\hline Psychosocial & $\begin{array}{l}4452 \\
(50.1)\end{array}$ & $\begin{array}{l}3872 \\
(47.7)\end{array}$ & $\begin{array}{l}580 \\
(74.9)\end{array}$ & $<0.001$ \\
\hline Primary care & $\begin{array}{l}6165 \\
(69.4)\end{array}$ & $\begin{array}{l}5586 \\
(68.8)\end{array}$ & $\begin{array}{l}579 \\
(74.8)\end{array}$ & $<0.001$ \\
\hline $\begin{array}{l}\text { Emergency } \\
\text { department }\end{array}$ & $\begin{array}{l}1865 \\
(21.0)\end{array}$ & $\begin{array}{l}1658 \\
(20.4)\end{array}$ & $\begin{array}{l}207 \\
(26.7)\end{array}$ & $<0.001$ \\
\hline Other outpatient§ & $\begin{array}{l}7200 \\
(81.0)\end{array}$ & $\begin{array}{l}6552 \\
(80.7)\end{array}$ & $\begin{array}{l}648 \\
(83.7)\end{array}$ & $<0.001$ \\
\hline Any inpatient & $398(4.5)$ & $343(4.2)$ & $55(7.1)$ & $<0.001$ \\
\hline $\begin{array}{l}\text { Median (IQR) } \\
\text { number of outpa- } \\
\text { tient encounters, } \\
\text { among those with } \\
\text { any }\end{array}$ & $8(4,15)$ & $7(3,14)$ & $\begin{array}{l}11(5, \\
20)\end{array}$ & $<0.001$ \\
\hline
\end{tabular}

IPV intimate partner violence, IPV- E-HITS score of $<7$, IPV+ E-HITS score of $\geq 7, I Q R$ interquartile range

$* p$ value for IPV+ vs. IPV- is $<0.001$

† "Not married" includes divorced (27.6\% of total), never married (27.6\% of total), separated (5.1\% of total), and widowed (3.3\% of total) f "Psychosocial" visits include mental health, social work, drug or alcohol treatment, or homelessness services

$\S$ "Other outpatient" includes specialty care such as cardiology, endocrinology, gynecology, and ophthalmology

"l" Other" race includes Asian (1.0\% of total), Native Hawaiian or other Pacific Islander ( $0.6 \%$ of total), and multiple races (1.4\% of total)

When examining the number of visits within the 6-month time frame, among those with any visits, the IPV+ group had higher 
Table 2 Frequency of Service Utilization (Visits) by IPV Status from Estimated Zero-Inflated Poisson Models

\begin{tabular}{|c|c|c|c|c|}
\hline \multirow[b]{2}{*}{ Visit type: } & \multicolumn{2}{|c|}{ Unadjusted ZIP model } & \multicolumn{2}{|c|}{ Adjusted ZIP model§ } \\
\hline & $\begin{array}{l}\text { Logistic } \\
\text { zero } \\
\text { model: } \\
\text { Visit yes } \\
\text { vs. no } \\
\text { OR (95\% } \\
\text { CI) }\end{array}$ & $\begin{array}{l}\text { Poisson } \\
\text { count } \\
\text { model: } \\
\text { RR (95\% } \\
\text { CI) }\end{array}$ & $\begin{array}{l}\text { Logistic } \\
\text { zero } \\
\text { model: } \\
\text { Visit yes } \\
\text { vs. no } \\
\text { OR (95\% } \\
\text { CI) }\end{array}$ & $\begin{array}{l}\text { Poisson } \\
\text { count } \\
\text { model: } \\
\text { RR (95\% } \\
\text { CI) }\end{array}$ \\
\hline Any outpatient & $\begin{array}{l}1.85 \\
(1.27 \\
2.70)^{*}\end{array}$ & $\begin{array}{l}1.53 \\
(1.50 \\
1.56)^{*}\end{array}$ & $\begin{array}{l}1.85 \\
(1.26 \\
2.70)^{*}\end{array}$ & $\begin{array}{l}1.50 \\
(1.45 \\
1.55)^{*}\end{array}$ \\
\hline Psychosocial $\dagger$ & $\begin{array}{l}3.25 \\
(2.70, \\
3.93)^{*}\end{array}$ & $\begin{array}{l}1.47 \\
(1.42, \\
1.51)^{*}\end{array}$ & $\begin{array}{l}3.32 \\
(2.74, \\
4.01)^{*}\end{array}$ & $\begin{array}{l}1.50 \\
(1.45 \\
1.55)^{*}\end{array}$ \\
\hline Primary care & $\begin{array}{l}1.25 \\
(1.00 \\
1.57)\end{array}$ & $\begin{array}{l}1.20 \\
(1.14 \\
1.27)^{*}\end{array}$ & $\begin{array}{l}1.27 \\
(1.01 \\
1.61)^{*}\end{array}$ & $\begin{array}{l}1.24 \\
(1.17 \\
1.31)^{*}\end{array}$ \\
\hline $\begin{array}{l}\text { Emergency } \\
\text { department }\end{array}$ & $\begin{array}{l}1.25 \\
(0.96 \\
1.63)\end{array}$ & $\begin{array}{l}1.27 \\
(1.07 \\
1.50)^{*}\end{array}$ & $\begin{array}{l}1.27 \\
(0.97 \\
1.67)\end{array}$ & $\begin{array}{l}1.28 \\
(1.07 \\
1.52)^{*}\end{array}$ \\
\hline $\begin{array}{l}\text { Other } \\
\text { outpatient } \$\end{array}$ & $\begin{array}{l}1.21 \\
(0.97 \\
1.52)\end{array}$ & $\begin{array}{l}1.21 \\
(1.17 \\
1.25)^{*}\end{array}$ & $\begin{array}{l}1.22 \\
(0.98 \\
1.53)\end{array}$ & $\begin{array}{l}1.56 \\
(1.53, \\
1.60)^{*}\end{array}$ \\
\hline Any inpatient & $\begin{array}{l}1.53 \\
(0.95 \\
2.45)\end{array}$ & $\begin{array}{l}1.22 \\
(0.79 \\
1.87)\end{array}$ & $\begin{array}{l}2.09 \\
(1.23, \\
3.57)^{*}\end{array}$ & $\begin{array}{l}0.98 \\
(0.63 \\
1.53)\end{array}$ \\
\hline
\end{tabular}

ZIP zero inflated Poisson, OR odds ratio, $R R$ rate ratio, CI confidence interval

*Confidence interval for IPV+ vs. IPV- is $<1$

" "Psychosocial" visits include: mental health, social work, drug or alcohol treatment, or homelessness services

f"Other outpatient" includes specialty care such as cardiology, endocrinology, gynecology, ophthalmology, etc.

§Adjusted for age, race, marital status, and veteran status

frequency of service utilization compared with the IPV- group for each category of outpatient visits. Among those with any psychosocial encounters in the 6-month period, the IPV+ group had approximately $50 \%$ more visits than the IPV- group. There was no statistically significant difference between the two groups in frequency of inpatient stays.

\section{Service Utilization Among IPV+ Patients}

Figure 1 demonstrates the proportion of IPV+ patients who received each type of service within: $14,30,60$, and 180 days of the index IPV screen. Within 2 weeks (14 days) of the positive IPV screen, $70.9 \%$ of IPV+ patients had an additional outpatient visit beyond the visit in which they were screened, $46.1 \%$ had an encounter with a mental or behavioral health provider (psychosocial encounter), and $19.6 \%$ had a primary care visit. Nearly $4 \%$ of IPV+ patients had a visit to the emergency department within 2 weeks of the IPV screen; this proportion jumped to $8 \%$ within 1 month (30 days), $14.5 \%$ within 2 months, and $26.7 \%$ by 6 months.

\section{DISCUSSION}

This study presents new findings regarding health service utilization patterns following IPV screening in a routine clinical care setting among a large cohort of female patients. These findings indicate that the overwhelming majority of women in the VHA healthcare system who screen positive for IPV return for outpatient visits within a brief time frame following the screening visit (>70\% within 14 days and $>$ 95\% within 6 months), providing opportunities to offer follow-up support for IPV-related needs.

The positive association between screening positive for past-year IPV and increased health services use is consistent with prior literature ${ }^{10,13,14}$ and may be attributed to multiple factors. Women experiencing IPV may be more likely to utilize healthcare services due to IPV-related healthcare needs, such as physical or psychological effects of IPV exposure. A positive IPV screen may also prompt providers to offer or encourage follow-up care to address IPV-related needs, although we are unable to assess from this study whether or not those return visits indeed were used to address IPV. Additionally, women who have experienced IPV have emphasized the importance of feeling comfortable with a provider as a prerequisite to disclosing IPV experience ${ }^{29}, 30$; thus, those who have more frequent healthcare visits may be more comfortable and familiar with their providers, facilitating such disclosure.

Return outpatient visits following the visit during which the patient was screened offer opportunities for follow-up support and intervention. The fact that over $70 \%$ of patients screening IPV+ returned to a VHA provider within 2 weeks of a positive screen supports the feasibility of offering in-person follow-up services related to IPV. Although these return visits may not (and likely are not) all specifically in response to IPV screening, the fact that patients do return provides an opportunity for providers to check in with patients about IPV, offer resources or referrals, or conduct more formal or structured intervention.

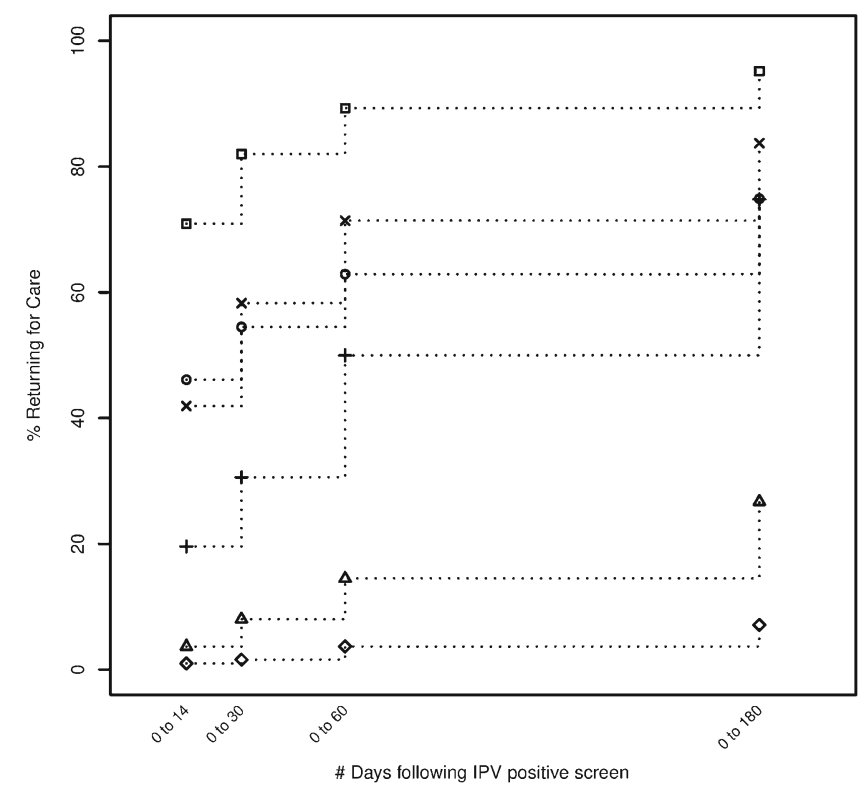

Fig. 1 Proportion of IPV+ patients receiving care within 6 months of IPV screen 
Such interventions may include in-depth assessment and safety planning, psychoeducational programming, counseling, and connection to community-based services.

That three quarters of the women who disclosed recent IPV experience received psychosocial care indicates high levels of access to services that may be appropriate for follow-up care. These may include both social services (e.g., housing support) and mental health treatment. Such services may lead to improved safety and health among women who experience IPV. ${ }^{33}$ We do not know from these data, however, if IPV experiences were addressed in these encounters or if these visits occurred because of the IPV screening response (i.e., patients referred to psychosocial support in response to IPV).

Emergency department visits among women screening IPV+ may provide an opportunity for emergency-based and brief interventions and may also indicate an IPV-related injury or crisis. Prior research has found elevated rates of emergency department use among women experiencing IPV and identified the emergency department as a primary intervention point for IPV-related concerns. ${ }^{31,32}$

This is the first study to examine healthcare service use among patients experiencing IPV utilizing health records data within the VHA healthcare system. Analysis of health records data from this system and population offers several unique contributions. Unlike prior studies of healthcare service utilization among women experiencing IPV,${ }^{10-14}$ this study (a) is not reliant on enrollment in or responses to research surveys; (b) examines healthcare utilization within an integrated system including mental, behavioral, and social health services; and (c) examines responses to routine healthcare screening for experience of recent (past-year) IPV. The VHA healthcare setting offers unique opportunities to study a large cohort of patients across the nation and service utilization across a variety of healthcare services (psychosocial, primary, specialty, emergency, and inpatient care).

This cohort only included patients currently receiving care at a VHA facility, which limits the generalizability of findings across populations and settings. Patients not served in the VHA may differ from those included in this study in both their healthcare service access and needs. Psychosocial care may be less readily available in a less- or non-integrated healthcare system. Additionally, this study focused only on VHA service use and does not capture service use or informal systems of support that women may have received outside of the VHA system. Analyses were limited to data available in the electronic health record and thus do not include all potential confounders of health services use such as patient attitudes, barriers to access, and additional sociodemographic characteristics. Further research identifying the full range of resources and supports utilized by women who screen positive for recent IPV is important to inform the needs and resources available to this population.

Next steps for research include gaining a better understanding of the focus of subsequent health service use and the impact of service use on patient health and functioning outcomes, including safety, health, and well-being over time. Additionally, future research should examine whether followup visits actually address IPV, in what ways, and the kinds of interventions that are useful to patients following disclosure of IPV in the healthcare setting.

Corresponding Author: Melissa E. Dichter, PhD; Center for Health Equity Research and Promotion U.S. Department of Veterans Affairs, Philadelphia, PA, USA (e-mail: Melissa.Dichter@va.gov).

Funding Information This study was funded by a grant from the U.S. Department of Veterans Affairs, Health Services Research and Development, IIR 15-142 (Dichter)

\section{Compliance with Ethical Standards:}

The study was approved by the Corporal Michael J. Crescenz VA Medical Center institutional review board, including a waiver of informed consent.

Disclaimer: The views expressed in this article are those of the authors and do not necessarily represent the position or policy of the Department of Veterans Affairs or the US Government.

Conflict of Interest: The authors declare that they do not have a conflict of interest.

\section{REFERENCES}

1. Black MC, Basile K, Breiding MJ, Smith SG, Walters ML, Merrick MT, et al. The National Intimate Partner and Sexual Violence Survey (NISVS): 2010 Summary Report. Atlanta, GA: National Center for Injury Prevention and Control, Centers for Disease Control and Prevention; 2011.

2. Beydoun HA, Beydoun MA, Kaufman JS, Lo B, Zonderman AB. Intimate partner violence against adult women and its association with major depressive disorder, depressive symptoms and postpartum depression: a systematic review and meta-analysis. Soc Sci Med 2012;75(6):959-75. https://doi.org/10.1016/j.socscimed.2012.04.025.

3. Bonomi AE, Anderson ML, Reid RJ, Rivara FP, Carrell D, Thompson RS. Medical and psychosocial diagnoses in women with a history of intimate partner violence. Arch Intern Med 2009;169(18):1692-7. https://doi.org/10.1001/archinternmed.2009.292.

4. Dichter ME, Cerulli C, Bossarte RM. Intimate partner violence victimization among women veterans and associated heart health risks. Womens Health Issues 2011;21(4 Suppl):S190-4. https://doi.org/10. 1016/j.whi.2011.04.008

5. Lagdon S, Armour C, Stringer M. Adult experience of mental health outcomes as a result of intimate partner violence victimisation: a systematic review. Eur J Psychotraumatol. 2014;5. https://doi.org/10. 3402/ejpt.v5.24794.

6. Dichter ME, Sorrentino A, Bellamy S, Medvedeva E, Roberts CB, Iverson KM. Disproportionate mental health burden associated with past-year intimate partner violence among women receiving care in the Veterans Health Administration. J Trauma Stress 2017;30(6):555-563. https://doi.org/10.1002/jts.22241.

7. Dichter ME, Rhodes KV. Intimate partner violence survivors' unmet social service needs. J Soc Serv Res 2011;37(5):481-9. https://doi.org/ 10.1080/01488376.2011.587747

8. Ansara DL, Hindin MJ. Formal and informal help-seeking associated with women's and men's experiences of intimate partner violence in Canada. Soc Sci Med 2010;70(7):1011-8. https://doi.org/10.1016/j. socscimed.2009.12.009.

9. Adams AE, Tolman RM, Bybee D, Sullivan CM, Kennedy AC. The impact of intimate partner violence on low-income women's economic well-being: the mediating role of job stability. Violence Against Women 2012;18(12):1345-67. https://doi.org/10.1177/1077801212474294.

10. Bonomi AE, Anderson ML, Rivara FP, Thompson RS. Health care utilization and costs associated with physical and nonphysical-only intimate partner violence. Health Serv Res 2009;44(3):1052-67. https://doi.org/10.1111/j.1475-6773.2009.00955.x. 
11. Fishman PA, Bonomi AE, Anderson ML, Reid RJ, Rivara FP. Changes in health care costs over time following the cessation of intimate partner violence. J Gen Intern Med 2010;25(9):920-5. https://doi.org/10.1007/ s11606-010-1359-0.

12. Jones AS, Dienemann J, Schollenberger J, Kub J, O'Campo P, Gielen AC, et al. Long-term costs of intimate partner violence in a sample of female HMO enrollees. Womens Health Issues 2006;16(5):252-61. https://doi.org/10.1016/j.whi.2006.06.007.

13. Rivara FP, Anderson ML, Fishman P, Bonomi AE, Reid RJ, Carrell D, et al. Healthcare utilization and costs for women with a history of intimate partner violence. Am J Prev Med 2007;32(2):89-96. https://doi org/10.1016/j.amepre.2006.10.001.

14. Dichter ME, Marcus SC. Intimate partner violence victimization among women veterans: Health, health care service use, and opportunities for intervention. Mil Behav Health 2013;1(2):107-113. https://doi.org/10. 1080/21635781.2013.830062.

15. Chamberlain L, Levenson $\mathbf{R}$. Addressing Intimate Partner Violence, Reproductive and Sexual Coercion: A Guide for Obstetric, Gynecologic and Reproductive Health Care Settings. Second ed. San Francisco, CA: Futures Without Violence; 2012.

16. Family Violence Prevention Fund. National Consensus Guidelines on Identifying and Responding to Domestic Violence Victimization in Health Care Settings. San Francisco, CA: The Family Violence Prevention Fund; 2004.

17. Feldman MD. Screening for intimate partner violence: the time is now. J Gen Intern Med 2013;28(10):1251-2. https://doi.org/10.1007/s11606013-2576-0.

18. Klap R, Tang L, Wells K, Starks SL, Rodriguez M. Screening for domestic violence among adult women in the United States. J Gen Intern Med 2007;22(5):579-84. https://doi.org/10.1007/s11606-006-0097-9.

19. Littel K. Family violence: an intervention model for dental professionals. OVC Bulletin. December 2004: US Department of Justice, Office of Justice Programs, Office for Victims of Crime; 2004.

20. McAlister Groves B, Augustyn M, Lee D, Sawires P. Identifying and Responding to Domestic Violence: Consensus Recommendations for Child and Adolescent Health. San Francisco, CA: Family Violence Prevention Fund; 2004

21. National Center on Domestic Violence Trauma \& Mental Health. Responding to Domestic Violence: Tools for Mental Health Providers. National Center on Domestic Violence, Trauma \& Mental Health; 2004.

22. Rhodes KV, Kothari CL, Dichter M, Cerulli C, Wiley J, Marcus S. Intimate partner violence identification and response: time for a change in strategy. J Gen Intern Med 2011;26(8):894-9. https://doi.org/10.1007/ s11606-011-1662-4.
23. Iverson KM. Routine screening for intimate partner violence in VHA: a timely opportunity. J Gen Intern Med 2014;29(2):280. https://doi.org/ 10.1007/s11606-013-2716-6.

24. Kimerling $\mathbf{R}$, Iverson KM, Dichter ME, Rodriguez AL, Wong A, Pavao J. Prevalence of intimate partner violence among women veterans who utilize Veterans Health Administration primary care. J Gen Intern Med 2016;31(8):888-94. https://doi.org/10.1007/s11606-016-3701-7.

25. Dichter ME, Haywood TN, Butler AE, Bellamy SL, Iverson KM. Intimate partner violence screening in the Veterans Health Administration: demographic and military service characteristics. Am J Prev Med 2017;52(6):761-8. https://doi.org/10.1007/s11606-016-3701-7.

26. Chan C, Chan Y, Au A, Cheung G. Reliability and validity of the 'Extended-Hurt, Insult, Threaten, Scream' (E-HITS) screening tool in detecting intimate partner violence in hospital emergency departments in Hong Kong. Hong Kong J Emer Med 2010;17(2):109-17.

27. Iverson KM, King MW, Gerber MR, Resick PA, Kimerling R, Street AE, et al. Accuracy of an intimate partner violence screening tool for female VHA patients: a replication and extension. J Trauma Stress 2015;28(1):79-82. https://doi.org/10.1002/jts.21985.

28. Frayne S, Phibbs C, Saechao F, Maisel N, Friedman S, Finlay A, et al. Sourcebook: Women Veterans in the Veterans Health Administration. Volume 3. Sociodemographics, Utilization, Costs of Care, and Health Profile. Washington, DC: Veterans Health Administration, Department of Veterans Affairs; 2014

29. Dichter ME, Wagner C, Goldberg EB, Iverson KM. Intimate partner violence detection and care in the Veterans Health Administration: patient and provider perspectives. Womens Health Issues 2015;25(5):555-60. https://doi.org/10.1016/j.whi.2015.06.006.

30. Iverson KM, Huang K, Wells SY, Wright JD, Gerber MR, WiltseyStirman S. Women veterans' preferences for intimate partner violence screening and response procedures within the Veterans Health Administration. Res Nurs Health 2014;37(4):302-11. https://doi.org/10.1002/ nur.21602.

31. Kothari CL, Rohs T, Davidson S, Kothari RU, Klein C, Koestner A, et al. Emergency department visits and injury hospitalizations for female and male victims and perpetrators of intimate partner violence. Adv Emer Med 2015. https://doi.org/10.1155/2015/502703.

32. Lipsky S, Caetano R. The role of race/ethnicity in the relationship between emergency department use and intimate partner violence: Findings from the 2002 National Survey on Drug Use and Health. Am J Public Health 2007;97(12):2246-52. https://doi.org/10.2105/AJPH. 2006.091116.

33. McCloskey LA, Lichter E, Williams C, Gerber M, Wittenberg E, Ganz M. Assessing intimate partner violence in health care settings leads to women's receipt of interventions and improved health. Public Health Rep 2006;121(4):435-44. https://doi.org/10.1177/003335490612100412. 